\title{
Effects of sediment-associated phenanthrene on survival, development and reproduction of two species of meiobenthic copepods
}

\author{
Guilherme R. Lotufo*, John W. Fleeger \\ Department of Zoology and Physiology, Louisiana State University, Baton Rouge, Louisiana 70803, USA
}

\begin{abstract}
The lethal and sublethal toxicity of phenanthrene (a polycyclic aromatic hydrocarbon, PAH) to 2 species of meiobenthic estuarine harpacticoid copepods (Schizopera knabeni and Nitocra lacustris) was investigated. Individuals of different life stages (nauplius, copepodite, adult male and female) were exposed to sediment-associated phenanthrene in separate $10 \mathrm{~d}$ bioassays. Overall, $N$. lacustris (10 d LC 50 values ranging from 43 to $105 \mathrm{\mu g} \mathrm{g}^{-1}$ dry wt) was more sensitive than $S$. knabeni (10 d LC $\mathrm{LC}_{50}$ values ranging from 84 to $349 \mathrm{\mu g} \mathrm{g}^{-1}$ dry wt). Significant differences in life-stage-specific sensitivity were observed for $S$. knabeni, with the nauplii being most sensitive, followed by copepodites, and adults; adult males and females were equally sensitive. For $N$. lacustris, females were significantly more sensitive than all other stages; no significant differences were evident among the other stages. Phenanthrene effects on offspring production were investigated in the adult $10 \mathrm{~d}$ bioassay. Significant decreases in offspring production occurred at sublethal concentrations for $S$. knabeni (as low as $22 \mu \mathrm{g} \mathrm{g}{ }^{-1} \mathrm{dry} w \mathrm{t}$ ), but at concentrations in the same range as the $10 \mathrm{~d} \mathrm{LC}_{50}$ values for $\mathrm{N}$. lacustris. In addition, phenanthrene signuficantly prolonged embryonic and larval development and decreased egg hatching success for both species. Our results suggest that PAHs have a negative effect on the reproduction of meiobenthic copepods at sublethal concentrations mostly due to a decrease in brood production rate and impairment of hatching. Overall, deleterious effects were manifested in the same range of concentrations for both species, but definite species-specific differences in the pattern of responses were evident.
\end{abstract}

KEY WORDS: Sediment toxicity $\cdot$ Copepod $\cdot$ Life history $\cdot$ Meiobenthos $\cdot$ Phenanthrene

\section{INTRODUCTION}

Polycyclic aromatic hydrocarbons (PAHs) are among the most carcinogenic, mutagenic and toxic contaminants found in aquatic systems. An estimated $2.3 \times$ $10^{6} \mathrm{t}$ of PAHs enter aquatic systems every year (Kennish 1992). Phenanthrene is a medium-molecularweight PAH composed of 3 benzene rings and is an important environment contaminant (U.S. EPA 1993). The lethal toxicity of phenanthrene to numerous species of invertebrates and fish in aqueous exposures

\footnotetext{
- Present address: National Oceanic and Atmospheric Administration, Great Lakes Environmental Research Laboratory, 2205 Commonwealth Blvd, Ann Arbor, Michigan 48105,

USA.E-mail: lotufo@glerl.noaa.gov
}

(96 $\mathrm{h} \mathrm{LC}_{50}$ values ranging from 17.7 to $>1150 \mu \mathrm{g} \mathrm{l}^{-1}$ ) is summarized by the U.S. EPA (1993). Studies on the sublethal toxicity of phenanthrene report such effects as increased respiration rate and decreased growth and larval development rate, offspring production and feeding rate (Laughlin \& Neff 1979, 1980, Geiger \& Buikema 1981, 1982, Donkin et al. 1989, Emery \& DilIon 1996). Due to their high hydrophobicity, phenanthrene and other PAHs in the water column are rapidly sequestered into the organic matrix of suspended sediments and bed sediments, resulting in sediment contamination. Reports of the toxicity of sedimentassociated phenanthrene to infaunal invertebrates are scarce, including lethal toxicity to amphipods (U.S. EPA 1993) and decreased survival, feeding rate and reproductive output of tubificid worms (Lotufo \& 
Fleeger 1996) and harpacticoid copepods (Lotufo 1997).

Copepods have been largelv employed in water-only toxicity bioassays (e.g Bengtsson \& Tarkpea 1995). including early-life-stage exposures (Verriopoulus \& Moraitou-Apostolopoulou 1982, O'Brien et al. 1988, Hutchinson et al. 1994) and life-table studies (Daniels \& Allan 1981, Allan \& Daniels 1982, Bechmann 1994). Harpacticoid copepods are also well suited for sediment-toxicity assessment. Methods for culturing and use in toxicity bioassays have been described (e.g. Chandler \& Green 1996, Lotufo 1997). Most species undergo a short life cycle and all larval stages are infaunal, making them excellent test organisms for assessing the effects of sediment-associated contaminants on life-history traits. Investigations employing copepod life-history-related endpoints in sediment exposures include reproductive output (Chandler 1990. Strawbridge et al. 1992. DiPinto et al. 1993, Chandler \& Green 1996), life-stage-specific survival (Green et al. 1996) and a partial life-table study (Green \& Chandler 1996)

Decreased offspring production was observed at sublethal concentrations when copulating pairs of Schizopera knabeni were exposed for $14 \mathrm{~d}$ to PAHamended sediments (Lotufo 1997). However, it was not possible to discern the specific causes of the decrease. The reduction in reproductive output could have been due to changes in egg production rate, hatching success or early-stage survival, alone or in combination. The objective of the present study was to enhance the understanding of the effects of PAHs on the life-history of meiobenthic copepods. The lethal and sublethal toxicities of phenanthrene to 2 species, $S$. knabeni and Nitocra lacustris, were investigated and compared. Both harpacticoid copepod species inhabit the upper zone of intertidal mudflats of salt marshes of the Atlantic and Pacific coasts of the USA. Both species complete a full life cycle in less than $21 \mathrm{~d}$ at $25^{\circ} \mathrm{C}$ and are easily cultured under laboratory conditions. Ten day exposures, starting with different life stages (nauplius, copepodite, or adult), were conducted to investigate phenanthrene effects on life-stage-specific survival, development, offspring production, clutch size and hatching success.

\section{METHODS}

Culture conditions. Schizopera knabeni Lang and Nitocra lacustris (Schmankevitsch) were obtained from mono-specific laboratory cultures started with stock collected from the surface sediment of intertidal mudflats in a Spartina alterniflora salt marsh at Port Fourchon, Louisiana, USA. S. knabeni has been cultured since October 1993 and $N$. lacustris since February 1995. They were cultured sediment-free in $500 \mathrm{ml}$ Erlenmeyer flasks at room temperature with $350 \mathrm{ml}$ of $25 \%$ artificial seawater (ASW; Instant Ocean, Aquarium Systems, Mentor, OH, USA) in static conditions without aeration. The light regime was approximately $12 \mathrm{~h}$ light: $12 \mathrm{~h}$ dark. The medium was renewed every $14 \mathrm{~d}$ and food was added twice a week as $3 \mathrm{ml}$ (approximately $15 \mathrm{mg}$ dry $w \mathrm{t}$ ) of a mixture (8:2, dry wt : dry wt) of Chaetoceros muelleri (a planktonic diatom), and Microfeast Plus Larval Diet (Provesta Corporation, Bartlesville, OK, USA). Adult copepod density in culture flasks maintained under these conditions was typically 1 to $3 \times 10^{3}$ individuals.

Partial life-cycle observations. The offspring production of Schizopera knabeni and Nitocra lacustris was monitored daily for $10 \mathrm{~d}$. Six copulating pairs of $S$. knabeni and non-copulating pairs of $N$. lacustris were kept in small dishes (1 pair per dish) containing uncontaminated 25\% ASW without sediment. Copulating pairs consisting of an adult male clasping a preadult female (copepodite $V$ ) were abundant for $S$. knabeni but rare for $N$. lacustris. The use of dishes with water only allowed direct observation and accurate determination of life-history features such as the timing and frequency of egg-sac extrusion and hatching, and the per-brood and total nauplii production during $10 \mathrm{~d}$. Copepods were kept at $25^{\circ} \mathrm{C}$ and fed $0.1 \mathrm{ml}(0.5 \mathrm{mg}$ dry $\mathrm{wt}$ ) of Chaetoceros muelleri every other day. Adults were observed and transferred to new dishes daily. Naupli.i were enumerated and removed from the dish as soon as their presence was detected. For each species, 4 groups of 15 newborn nauplii of each species were also observed daily throughout their development to adulthood

Test organisms. Individuals at distinct life stages were used in 10 d bioassays to determine life-stagespecific responses to contamination. Copepods were removed from the culture and copulating pairs or single adults (males and non-ovigerous females) were sorted under a stereo microscope and used in the male/non-ovigerous female bioassays (see below) Approximately 100 ovigerous females were kept in loosely covered crystallizing dishes and fed $1 \mathrm{ml}(5 \mathrm{mg}$ dry wt) of Chaetoceros muelleri. Eggs started hatching within a few hours. After $48 \mathrm{~h}$, all females were removed and nauplii ( 1 or 2 d old) were sorted and immediately used in the nauplius bioassays (see below). Eight or nine day old copepodites were obtained from the same dishes $7 \mathrm{~d}$ after the removal of adults. At the end of this period, all offspring had metamorphosed to early copepodite stages and were immediately used in the copepodite bioassays (see below).

Sediment dosing. Sediment was collected from the top $2 \mathrm{~cm}$ of a mudflat in a Spartina alterniflora salt 
marsh near Cocodrie, Louisiana. The typical total PAH $( \pm \mathrm{SD})$ concentration in this sediment is $0.24 \pm 0.012 \mu \mathrm{g}$ $\mathrm{g}^{-1}$ dry wt (Carman et al. 1995). Stock test-sediment was prepared by sieving the mud through a $45 \mu \mathrm{m}$ mesh. The sediment that passed through the sieve was left to settle overnight at $4^{\circ} \mathrm{C}$. The supernatant was removed by aspiration, and the sediment was autoclaved. A liquid slurry (dry to wet wt ratio $=0.15$ ) was created by homogenizing the autoclaved sediment with the appropriate volume of $25 \%$ ASW. Sediments with similar dry to wet wt ratios are routinely used in sediment-toxicity tests with meiobenthic copepods (Chandler \& Green 1996). Total solids was determined by oven drying sediment samples at $80^{\circ} \mathrm{C}$. The sediment organic carbon (SOC) of the resultant slurry, measured in duplicate on a Perkin Elmer (Norwalk, CT, USA) 2400 CHN Elemental Analyzer, was 1.5\% after acidification with $\mathrm{HCl}$ to remove inorganic carbonate.

Phenanthrene $198 \%$ purity, Aldrich Chemical Co., Milwaukee, WI, USA) was added to the sediment slurry by spiking. Homogenized stock test-sediment $(150 \mathrm{~g}$ wet $\mathrm{wt}$, dry to wet wt ratio $=0.15)$ was transferred to each of nine $500 \mathrm{ml}$ beakers and vigorously stirred. The appropriate amount of phenanthrene, carried in $0.2 \mathrm{ml}$ of acetone, was added to the slurry and stirred for $4 \mathrm{~h}$. The required amount of spiked phenanthrene was calculated on a dry weight basis. Target concentrations were: $12.5,25,50,100,200,300,500$, and $750 \mathrm{\mu g} \mathrm{g}^{-1}$ dry wt. A control was prepared by adding $0.2 \mathrm{ml}$ of acetone only. Spiked sediment was stored at $4^{\circ} \mathrm{C}$. After settling overnight, the overlying water was removed by aspiration, replaced with fresh ASW and the sediment homogenized. This procedure was repeated twice and is expected to remove excess solvent (Landrum et al. 1994). Sediments were stored in the dark at $4^{\circ} \mathrm{C}$ for 3 to $6 \mathrm{wk}$ and fully homogenized with the overlying water before use. Phenanthrene sediment concentrations were measured by reversephase HPLC as described in Lotufo \& Fleeger (1996), and determined to be $0,11 \pm 2$ (mean \pm SD), $22 \pm 5,45$ $\pm 7,90 \pm 7,177 \pm 13,217 \pm 20,492 \pm 45$, and $739 \pm 78$ $\mu \mathrm{g} \mathrm{g}^{-1}$ dry wt. The mean extraction recovery was $87 \%$

Toxicity bioassays. In all bioassays, copepods were exposed to sediment treatments in $50 \times 35 \mathrm{~mm}$ crystallizing dishes (Kimble, Toledo, OH, USA) filled with $25 \mathrm{ml}$ of $25 \%$ ASW. In each dish, $8 \mathrm{ml}$ of sediment treatment was dispensed to the bottom with a $5 \mathrm{ml}$ Finnpipette ${ }^{\otimes}$, creating a 3 to $4 \mathrm{~mm}$ sediment layer Food was added to each dish as $0.3 \mathrm{mg}$ of Microfeast Plus Larval Diet ${ }^{*}$ mixed in $0.1 \mathrm{ml}$ of $25 \%$ ASW. Dishes were placed inside loosely covered plastic containers. Soaked paper towels placed inside the containers created a humid environment to retard evaporation from experimental dishes. The plastic containers were kept overnight at $25^{\circ} \mathrm{C}$ in a temperature-controlled environmental chamber with no illumination before test organisms were added.

Ten day bioassays were conducted to determine stage-specific sensitivity to phenanthrene lethal effects as well as phenanthrene sublethal effects on reproduction and development. Separate experiments were conducted using Schizopera knabeni and Nitocra lacustris. Four replicates were used per concentration. For each species, 3 bioassays were conducted using male/non-ovigerous-female pairs, early-age nauplii, or early-age copepodites. For all bioassays, copepods were introduced to experimental units, which were then returned to plastic containers and kept inside an environmental chamber at $25^{\circ} \mathrm{C}$ for $10 \mathrm{~d}$. Bioassays were conducted in the dark to prevent PAH photoinduced toxicity. At test termination, the contents of each dish were separately sieved over a $45 \mu \mathrm{m}$ mesh sieve and the retained material was washed into a plastic cell-culture dish. To avoid disturbance to the test organisms, 5 additional experimental units containing control sediment were prepared to measure salinity (Reichert refractometer, Cambridge Instruments, Buffalo, NY, USA) and oxygen concentration (Orion 820 oxygen meter, Boston, MA, USA) at initiation and termination of the experiment.

Male/female bioassays were initiated with 10 copulating pairs of Schizopera knabeni or 10 non-copulating adult pairs (single males and non-ovigerous females) of Nitocra lacustris per replicate. Copulating pairs of $N$. lacustris were rare among individuals retrieved from the culture system, and therefore not available in sufficient number for their use in the bioassays. At test termination, surviving adults and produced offspring were fixed with $4 \%$ buffered formalin and stained with Rose Bengal. Adult copepods were subsequently sorted and offspring enumerated as described in Chandler \& Green (1996). Clutch size was determined by enumeration of the eggs in intact sacs detached from ovigerous females. S. knabeni carries 2 sacs, while $N$. lacustris carries only 1 sac. Nauplius bioassays were initiated with 15 individuals ( 1 or 2 d old) per replicate; all phenanthrene concentrations were used, except for 11 and $739 \mathrm{\mu g} \mathrm{g}^{-1}$ dry wt. Copepodite bioassays were initiated with 20 individuals $(8$ or $9 \mathrm{~d}$ old) per replicate; all treatments were used except for $739 \mu \mathrm{g} \mathrm{g}^{-1}$ dry wt. At test termination, all surviving individuals were enumerated and examined for developmental stage (nauplius, copepodite, adult male, or adult female) in both nauplius and copepodite bioassays.

In order to determine phenanthrene effects on embryonic development, ovigerous females obtained from the copepodite bioassays were individually placed in tissue-culture dishes $(35 \times 10 \mathrm{~mm})$ half filled 
with 25\% ASW (no sediment), fed $0.1 \mathrm{ml}(0.5 \mathrm{mg}$ dry wt) of Chaetoceros muelleri, and observed every $8 \mathrm{~h}$ until eggs hatched. Nauplii were enumerated when their presence was detected in the dishes. One ovigerous female from each replicate of the copepodite bioassay was used. The 90 and $177 \mu \mathrm{g} \mathrm{g}^{-1}$ dry wt treatments from the Schizopera knabeni bioassay yielded single ovigerous females from only 3 replicates and the $217 \mu \mathrm{g} \mathrm{g}^{-1}$ dry wt did not yield any ovigerous females. Because $S$. knabeni ovigerous females of the same age were carrying their first brood of eggs, their age at first reproduction (age when first brood hatched) could be determined. This determination was not possible for Nitocra lacustris, because some females had already produced their first brood when the observation period was initiated.

Statistical analysis. For each copepod species, separate experiments were conducted using individuals of different life stages (nauplius, copepodites or adults). Each of the following endpoints were analyzed using 1-way analysis of variance (ANOVA): (1) fraction of test organisms found live at experiment termination in each bioassay (male/female, nauplius and copepodite); (2) offspring production (number of offspring divided by the number of surviving females) in the male/female bioassay; (3) number of eggs carried per ovigerous female (clutch size) at test termination in the male/female bioassay; (4) fraction of total offspring comprised of realized offspring (nauplii + copepodites) and fraction of realized offspring comprised of copepodites in the male/female bioassay; (5) fraction of surviving copepods that attained copepodite stages in the Schizopera knabeni nauplius bioassay; (6) fraction of surviving copepods that attained the adult stage in the Nitocra lacustris nauplius bioassay and in the copepodite bioassays; and (7) fraction of surviving adults comprised of males at termination of the copepodite bioassays. In addition, the 1-way ANOVA was used to test for differences in time for egg hatching and number of eggs successfully hatching per brood from ovigerous females obtained at termination of the copepodite bloassays. Percentages were arcsine square-root transformed prior to analysis so that the data conformed to the assumption of homogeneity of variances. Phenanthrene treatments were compared with control treatments using Dunnett's 2 -tailed t-test $(\alpha=0.05)$. Ten day $\mathrm{LC}_{50}$ values were computed using the trimmed Spearman-Karber method (Hamilton et al. 1977). Insufficient partial mortality in most bioassays prevented the use of probit analysis. In order to compare and test for significant differences in the sensitivities of the 4 life stages (nauplius, copepodite, adult male, adult female) to phenanthrene, survivorship data for each copepod species were analyzed statistically. A 2-way ANOVA. using the split-plot design tested for the significance of 3 different effects on copepod survival in the presence of phenanthrene: the main unit effect (or the effect of life stage), the subunit effect (or the effect of contamination level), and the effect of the interaction of these 2 factors. Data for the $11 \mu \mathrm{gg}{ }^{\mathrm{i}}$ dry wt treatment were not available for naupliar stages and therefore were removed from the analysis. Of principal interest was the comparison of overall survival under each life stage in a pairwise fashion (female vs

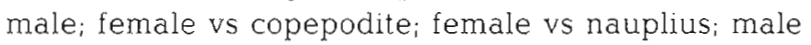
vs copepodite; male vs nauplius; and copepodite vs nauplius). However, if the interaction between life stage and contamination level was significant, the above pairwise comparisons were tested at each concentration level by calculating least significant differences according to Steel \& Torrie (1960). When the interaction effect was not significant but the effect of life stage was, pairwise comparisons among life stages were performed, again using Bonferroni adjustment for multiplicity (Steel \& Torrie 1960). The observed survival proportions $(y)$ were transformed via the angular transformation. (Green et al. 1996):

$$
y=\sqrt{(x+0.375) /(n+0.75)}
$$

where $r$ is the observed number of survivors and $n$ is the total number of organisms exposed in each replicate. The transformed proportions $(y)$ were used in the 2-way ANOVA. Statistical analyses were performed using TOXCALCTM version 5.0 (Tidepool Software, McKinleyville, CA, USA) and SAS software (Release 6.03 Edition; Cary, NC, USA).

\section{RESULTS}

\section{Partial life-cycle observations}

Daily observations of male/female pairs of Schizopera knabeni and Nitocra lacustris in uncontaminated water for $10 \mathrm{~d}$ indicated that egg clutches were first extruded after 2 to $3 \mathrm{~d}$ from the beginning of the observation period and hatched $1 \mathrm{~d}$ later The beginning of the observation period roughly coincided with the fertilization event for $S$. knabeni and with the period prior to the extrusion of an egg clutch for already fertilized $N$. lacustris. Each female S. knabeni produced $4.4 \pm 0.9$ (mean $\pm \mathrm{SD}$ ) clutches ( 1 every $2.4 \pm 0.5$ d) with $16.9 \pm$ 1.3 nauplii hatching from each brood. Nauplius production over $10 \mathrm{~d}$ was $73.5 \pm 15.3$, and clutch size of females ovigerous at Day 10 was $22.6 \pm 0.6$. N lacustris produced $3.7 \pm 0.5$ clutches ( 1 every $2.7 \pm 0.4 \mathrm{~d}$ ), with $15 \pm 1.6$ nauplii hatching per brood, and a total of 56.3 \pm 11 nauplii over $10 \mathrm{~d}$. Clutch size at Day 10 was $17.5 \pm$ 2.3. Four groups of fifteen $1 \mathrm{~d}$ old nauplii. of each 
Table 1 . Ten day median lethal concentrations $\mid \mathrm{LC}_{50}$ values; $\mathrm{ca}$ culated using the trimmed Spearman-Karber method (Hamilton et al. 1977) derived from bioassays starting with different life stages of Schizopera knabeni and Nitocra lacustris. Numbers in parentheses indicate $95 \%$ confidence intervals. All values expressed as $\mu \mathrm{g} \mathrm{g}^{-1}$ dry $w \mathrm{t}$

\begin{tabular}{|lcc|}
\hline LC $_{50}$ & Nitocra lacustris & Schizopera knabeni \\
\hline Female & $105(95-116)$ & $345(291-407)$ \\
Male & $72(62-83)$ & $349(291-417)$ \\
Copepodite & $43(36-52)$ & $172(155-190)$ \\
Naupluus & $71(65-77)$ & $84(74-96)$ \\
\hline
\end{tabular}

species were also observed daily. For $S$. knabeni, the copepodite stage was attained at age 7 to $8 \mathrm{~d}$. Sexual maturity was attained quickly; eggs were extruded at age 17 to $18 \mathrm{~d}$ and hatched at age 18 to $20 \mathrm{~d}$. For $N$. lacustris, the copepodite stage was attained at age 5 to $7 \mathrm{~d}$; eggs were extruded at age 14 to $16 \mathrm{~d}$ and hatched at age 16 to $18 \mathrm{~d}$.

\section{Lethal toxicity: life-stage sensitivity}

ANOVA indicated significant phenanthrene-treatment effects ( $p<0.05)$ on survivorship in all Nitocra lacustris and Schizopera knabeni $10 \mathrm{~d}$ bioassays. The salinity remained unchanged $(25 \%)$ throughout the $10 \mathrm{~d}$. Mean dissolved oxygen levels in the overlying water were $5.5 \pm 1.5 \mathrm{mg}^{-1}(79 \%$ saturation) at Day 0 and $5.2 \pm 1.2 \mathrm{mg} \mathrm{l}^{-1}$ (75\% saturation) at Day 10 .

For Nitocra lacustris, control survival was $>80 \%$ for all life stages (Fig. 1). Male survival was significantly lower than the control at $90 \mu \mathrm{g} \mathrm{g}^{-1} \mathrm{dry}$ wt and higher concentrations. Female survival was significantly lower than the control only at $177 \mu \mathrm{g} \mathrm{g}^{-1}$ dry wt and higher concentrations. Survival was significantly lower than the control at $22 \mu \mathrm{g} \mathrm{g}^{-1}$ dry wt and higher concentrations for copepodites and at $45 \mu \mathrm{g} \mathrm{g}^{-1}$ dry wt and higher concentrations for nauplii. No copepod survived exposure to $177 \mathrm{\mu g} \mathrm{g}^{-1}$ dry wt and higher concentrations (Fig. 1). The $10 \mathrm{~d} \mathrm{LC}_{50}$ values were $105 \mathrm{\mu g}$ $\mathrm{g}^{-1}$ dry wt for females, $72 \mu \mathrm{g} \mathrm{g}^{-1}$ dry wt for males, $43 \mu \mathrm{g}$ $\mathrm{g}^{-1}$ dry wt for copepodites, and $71 \mu \mathrm{g} \mathrm{g}^{-1}$ dry wt for nauplii (Table 1). Results from the 2-way AN()VA on copepod survival indicated a non-significant interaction between life stages and contamination level $(\mathrm{p}=$ 0.21 ) and a significant life-stage effect $(p<0.01)$; female survival was significantly higher than survival of all other life stages. Adult male, copepodite and naupliar survival were not significantly different (Table 2).

For Schizopera knabeni, mean adult survival was high in controls $197.5 \%$ for females and $100 \%$ for

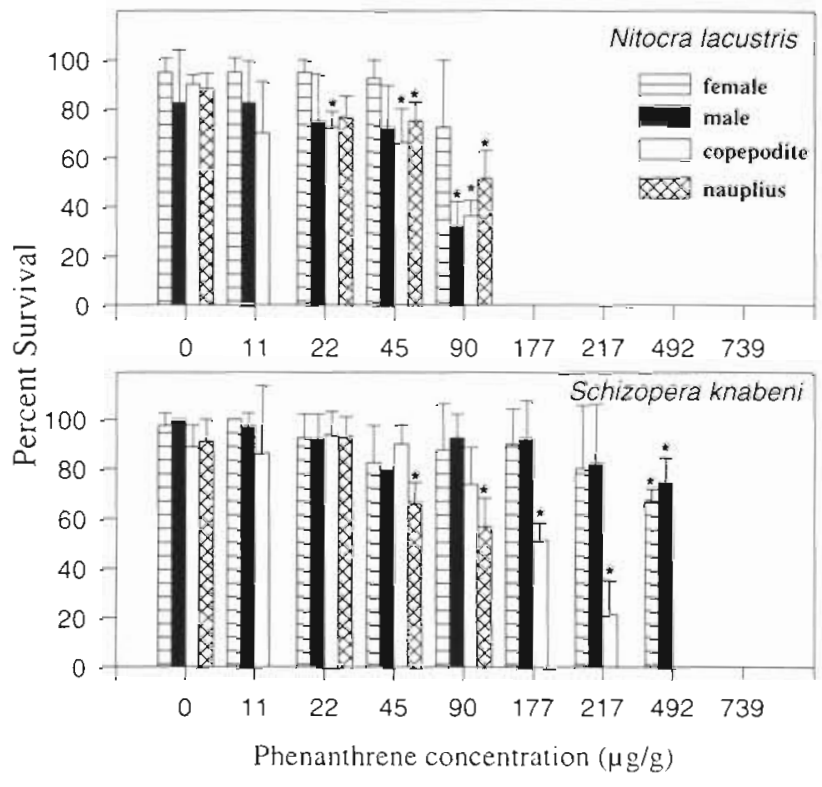

Fig. 1 Nitocra lacustris and Schizopera knabens. Survival of life stages (adult female, adult male, copepodite, and nauplius) exposed to sediment-associated phenanthrene for $10 \mathrm{~d}$. Error bars show $+1 \mathrm{SD}$ of the mean $(\mathrm{n}=4)_{i}{ }^{\star}$ significant difference $\{\alpha=0.05\}$ from control mean

males) and remained above $67.6 \%$ at concentrations from 11 to $492 \mu \mathrm{g} \mathrm{g}^{-1}$ dry wt. Survival of males and females was significantly lower than in the control only at $492 \mu g g^{-1}$ dry $w t$, and all adult copepods died during the exposure to $739 \mu \mathrm{g} \mathrm{g}^{-1}$ dry wt (Fig. 1). Mean

Table 2. Results of the statistical analysis comparing differences among the mean survival of different life stages of Schizopera knabeni and Nitocra lacustris exposed to sediment-associated phenanthrene. For $N$. lacustris, the 2-way A NOVA indicated a non-significant interaction between life stage and contamination level $(p=0.211$ ), and overall differences among life stages were analyzed. For $S$. knabeni, this interaction was significant $(\mathrm{p}<0.01)$, and differences among life stages were analyzed at each contamination level. Different letters indicate significant differences among life stages, overall or at each concentration. See 'Methods: Statistical analysis' for details

\begin{tabular}{|ccccc|}
\hline $\begin{array}{l}\text { Concentration } \\
\left(\mu \mathrm{g} \mathrm{g}^{-1} \mathrm{dry} w \mathrm{w}\right)\end{array}$ & Female & Male & $\begin{array}{c}\text { Cope- } \\
\text { podite }\end{array}$ & Nauplius \\
\hline $\begin{array}{l}\text { Nitocralacustris } \\
\text { Schizopera knabeni }\end{array}$ & $\mathrm{a}$ & $\mathrm{b}$ & $\mathrm{b}$ & $\mathrm{b}$ \\
0 & $\mathrm{a}$ & $\mathrm{a}$ & $\mathrm{a}$ & $\mathrm{a}$ \\
22 & $\mathrm{a}$ & $\mathrm{a}$ & $\mathrm{a}$ & $\mathrm{a}$ \\
45 & $\mathrm{a}$ & $\mathrm{a}$ & $\mathrm{a}, \mathrm{b}$ & $\mathrm{a}, \mathrm{c}$ \\
90 & $\mathrm{a}, \mathrm{b}$ & $\mathrm{a}$ & $\mathrm{b}$ & $\mathrm{c}$ \\
177 & $\mathrm{a}$ & $\mathrm{a}$ & $\mathrm{b}$ & $\mathrm{c}$ \\
217 & $\mathrm{a}$ & $\mathrm{a}$ & $\mathrm{b}$ & $\mathrm{c}$ \\
492 & $\mathrm{a}$ & $\mathrm{a}$ & $\mathrm{b}$ & $\mathrm{b}$ \\
& & & & \\
\hline
\end{tabular}


copepodite survival was high $(>87 \%)$ in the control and phenanthrene concentrations ranging from 11 to $45 \mu \mathrm{g} \mathrm{g}^{-1}$ dry wt and gradually decreased at higher concentrations; it was significantly lower than the control at 177 and $217 \mu \mathrm{g} \mathrm{g}^{-1}$ dry wt, and all copepodites died during exposure to 492 and $739 \mu \mathrm{g} \mathrm{g}^{-1}$ dry wt. Mean naupliar survival was high (>90\%) in the control and at $22 \mu \mathrm{g} \mathrm{g}^{-1}$ dry wt and decreased at higher phenanthrene concentrations; it was significantly lower than the control at 45 and $90 \mu \mathrm{g} \mathrm{g}^{-1}$ dry wt, and all nauplii died during exposure to $177 \mathrm{\mu g} \mathrm{g}^{-1}$ dry wt and higher concentrations. The $10 \mathrm{~d} \mathrm{LC}_{50}$ values were $345 \mu \mathrm{g} \mathrm{g}^{-1}$ dry wt for females, $349 \mu \mathrm{g} \mathrm{g}^{-1}$ dry wt for males, $172 \mu \mathrm{g} \mathrm{g}^{-1}$ dry wt for copepodites and $84 \mu \mathrm{g} \mathrm{g}^{-1}$ dry wt for nauplii (Table 1). Results from the 2-way ANOVA on S. knabeni survival indicated a significant interaction between life stages and contamination level $(\mathrm{p}<0.01)$. Adult male and female survival were not significantly different at any contamination level; naupliar survival was significantly lower than copepodite survival at $45 \mu \mathrm{g} \mathrm{g}^{-1}$ dry wt and higher concentrations, and lower than adult male and female survival at $90 \mu \mathrm{g} \mathrm{g}^{-1}$ dry wt and higher concentrations. Copepodite survival was significantly lower than adult male survival at $90 \mu \mathrm{g} \mathrm{g}^{-1}$ dry wt and lower than female survival at $177 \mu \mathrm{g} \mathrm{g}^{-1}$ dry wt and higher concentrations (Table 2). The $\mathrm{LC}_{50}$ values of adult females and males were practically identical. The $95 \%$ CI (confidence intervals) for the nauplius, copepodite and adult $\mathrm{LC}_{50}$ values did not overlap (Table 1.).

\section{Sublethal toxicity: offspring production}

ANOVA indicated significant phenanthrene-treatment effects ( $p<0.05$ ) on offspring production in the Nitocra lacustris and Schizopera knabeni male/female $10 \mathrm{~d}$ bioassays. Adult mortality took place in most replicates and increased with phenanthrene concentration. In order to more accurately assess sublethal effects on reproductive output, mean offspring production was calculated on a per-surviving-female basis. The standing stock of unhatched eggs at the termination of the $10 \mathrm{~d}$ exposure was determined by measuring the clutch size of surviving ovigerous females. Nauplii and copepodites surviving exposure comprised the realized offspring; nauplii and copepodites plus the unhatched eggs comprised the total or potential of fspring (Chandler \& Green 1996).

For Nitocra lacustris, the mean number of realized offspring was highest (not significantly) at 11 and $22 \mathrm{\mu g} \mathrm{g}^{-1}$ dry wt, followed by the control, 45 and $90 \mu \mathrm{g}$ $\mathrm{g}^{-1}$ dry wt treatments (Fig. 2); it was significantly lower than in the control only at $90 \mu \mathrm{g} \mathrm{g}^{-1}$ dry wt. The mean fraction of total offspring comprised of realized off-

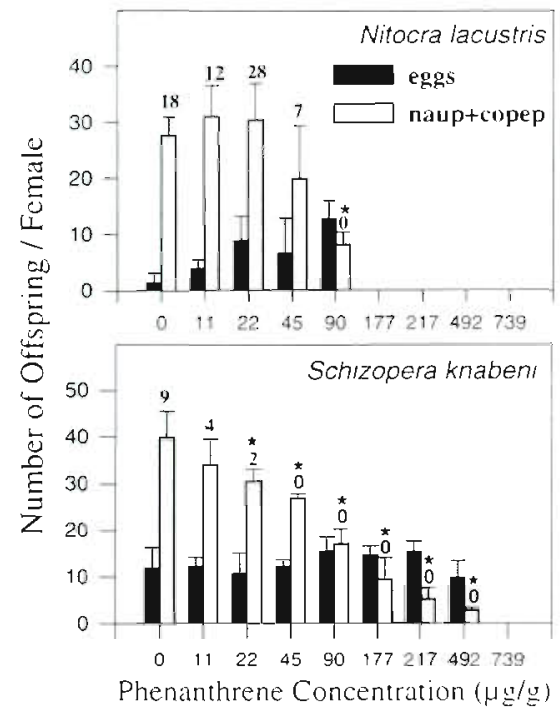

Fig. 2. Nitocra lacustris and Schizopera knabeni. Number of offspring produced by exposed to sediment-associated male/female pairs phenanthrene for $10 \mathrm{~d}$. Offspring were fractionated into eggs carried by surviving females and realized offspring [nauplii (naup) plus copepodites (copep)] present at test termination. Error bars show $+1 \mathrm{SD}$ of the mean (n $=4)_{i}$ * significant difference $(\alpha=0.05)$ from control mean for number of eggs or realized offspring; numbers over bars indicate the mean percentage of realized offspring comprised of copepodites. No $N$. Iacustris survived exposure to $177 \mathrm{\mu g} \mathrm{g}^{-1}$ dry wt and higher concentrations and no $S$. knaben survived exposure to the $739 \mathrm{\mu g} \mathrm{g}^{-1}$ dry wt treatment

spring was significantly lower than the control at 45 and $90 \mu \mathrm{g} \mathrm{g}^{-1}$ dry wt. The mean fraction of realized offspring comprised of copepodites was significantly lower than in the control at 45 and $90 \mu g g^{-1}$ dry wt (Fig. 2). Clutch size (data not shown) ranged from 15.4 to 17.9 and was not significantly different among sediment treatments $(\mathrm{p}=0.59)$.

For Schizopera knabeni, the mean number of realized offspring was significantly lower than in the control for all phenanthrene treatments except $11 \mu \mathrm{g} \mathrm{g} \mathrm{g}^{-1}$ dry wt (Fig. 2). The mean fraction of the total offspring comprised of realized offspring was significantly lower than the control at $177 \mu \mathrm{g} \mathrm{g}^{-1}$ dry wt and higher concentrations. The mean fraction of realized offspring comprised of copepodites was significantly lower than in the control for all phenanthrene treatments except $11 \mu \mathrm{Hg} \mathrm{g}^{-1}$ dry wt. No copepodites were found at concentrations of $45 \mu \mathrm{g} \mathrm{g} \mathrm{g}^{-1}$ dry wt and higher. Mean clutch size (data not shown) was highest in the control (19.9) and ranged from 16.6 to 18.9 in phenanthrene treatments up to $217 \mu \mathrm{g} \mathrm{g} \mathrm{g}^{-1}$ dry $\mathrm{wt}$, none of which were significantly different from the control. Mean clutch size in the $492 \mu \mathrm{g} \mathrm{g}^{-1} \mathrm{dry}$ wt treatment (12.1) was significantly lower than in the control. 


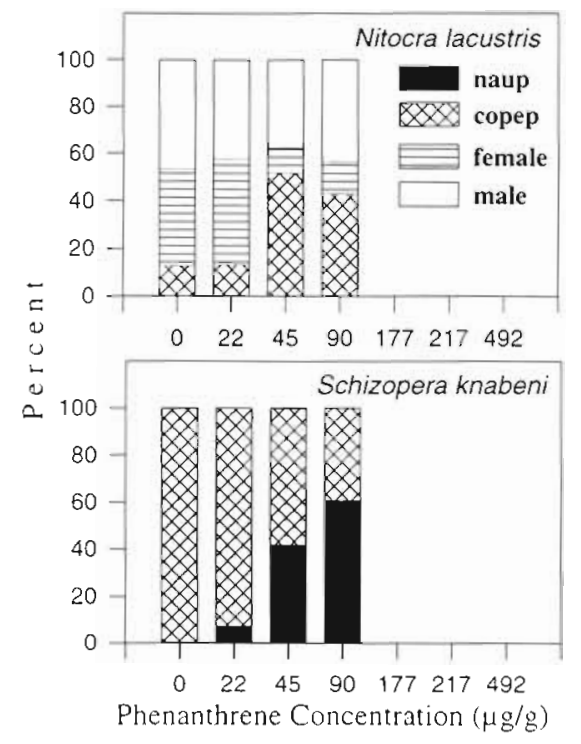

Fig. 3. Nitocra lacustris and Schizopera knabenı. Distribution of surviving copepods among life stages in the $10 \mathrm{~d}$ nauplius bioassay. Naup: nauplius; copep: copepodite; female: adult female; male: adult male. No nauplii survived exposure to the 177,217 and $492 \mu \mathrm{g} \mathrm{g}^{-1}$ dry wt treatments

\section{Sublethal toxicity: development}

Effects of phenanthrene on the development rate of larval and juvenile copepods over $10 \mathrm{~d}$ were examined in the nauplius and copepodite bioassays by identification of life stage at the end of the exposure period. In the Nitocra lacustris nauplius bioassay (Fig. 3), the fraction of surviving copepods that attained the adult stage in $10 \mathrm{~d}$ was highest in the control and $22 \mu \mathrm{g} \mathrm{g}^{-1}$ dry wt treatments $(88 \%)$ and significantly lower than the control at 45 and $90 \mu \mathrm{g} \mathrm{g}^{-1}$ dry wt. Males comprised approximately $50 \%$ of the adult copepods in the control and $22 \mu \mathrm{g} \mathrm{g}^{-1}$ dry wt treatments (sex ratio near $1: 1$ ). The mean fraction of males was higher than in the control in the 45 and $90 \mu \mathrm{g} \mathrm{g}^{-1}$ dry wt treatments $(77$ and $78 \%$, respectively), but not significantly. In the Schizopera knabeni nauplii bioassay (Fig 3), all surviving individuals in the control replicates metamorphosed to copepodites in $10 \mathrm{~d}$. However, copepods still in naupliar stages were observed at test termination in all phenanthrene treatments. The mean fraction of surviving copepods attaining copepodite stages decreased with phenanthrene concentration and was significantly lower than in the control at 45 and $90 \mu \mathrm{g} \mathrm{g} \mathrm{g}^{-1}$ dry wt.

In the Nitocra lacustris copepodite bioassay (Fig 4), all surviving copepods developed to adult stages in the control treatment; however, a fraction ranging from 12 to $17 \%$ remained in copepodite stages in all phenanthrene treatments. The fraction of individuals attaining

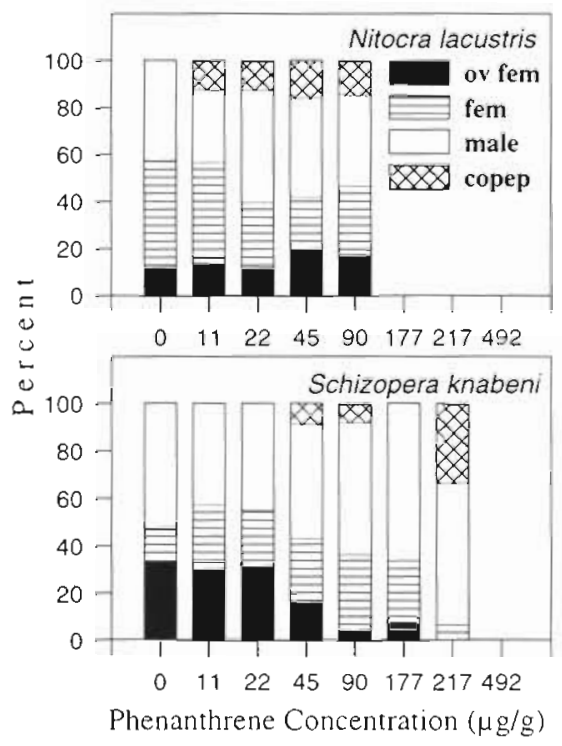

Fig. 4. Nitocra lacustris and Schizopera knabeni. Distribution of surviving copepods among life stages in the $10 \mathrm{~d}$ copepodite bioassay. Ov fem: oviçeraus female; fem: non-ovigerous adult female; male: adult male; copep: copepodite. No copepodite.$N$. lacustris survived expusure to the 177,217 and $492 \mu \mathrm{g} \mathrm{g}$ dry wt treatments and no copepodite $S$. knabeni survived exposure to the $492 \mathrm{\mu g} \mathrm{g}^{-1}$ dry wt treatment

adult stage was not significantly different among treatments $(p=0,17)$. Early-age nauplii were present in some replicates of all treatments, indicating offspring production by exposed copepods (data not shown). The sex ratio was near $1: 1$ across treatments, with males comprising from 39 to $55 \%$ of the adults. In the Schizopera knabeni copepodite bioassay (Fig. 4), all surviving copepods had developed to adult stages at experiment termination in all treatments except 45,90 and $217 \mathrm{\mu g} \mathrm{g}^{-1}$ dry wt, where individuals still at a copepodite stage were found. The fraction of surviving copepods comprised of adults was significantly lower than in the control at $217 \mu \mathrm{g} \mathrm{g}^{-1}$ dry wt. Ovigerous females comprised $70 \%$ of the total number of females found in the control. This fraction tended to decrease with increasing phenanthrene concentration and was significantly lower than in the control at 90 and $177 \mu \mathrm{g}$ $\mathrm{g}^{-1} \mathrm{dry}$ wt. The proportion of adults comprised of males was $53 \%$ in the control. This fraction increased with increasing phenanthrene concentrations (up to $89 \%$ ), but never significantly.

Periodic visual observation of ovigerous females obtained in the copepodite bioassay suggested an increase in the embryo maturation period in the presence of phenanthrene. For Nitocra lacustris, hatching occurred in the control after an average period of $1.5 \mathrm{~d}$ from the beginning of the observation period. Mean time for hatching was significantly longer (up to $3.8 \mathrm{~d}$ ) 


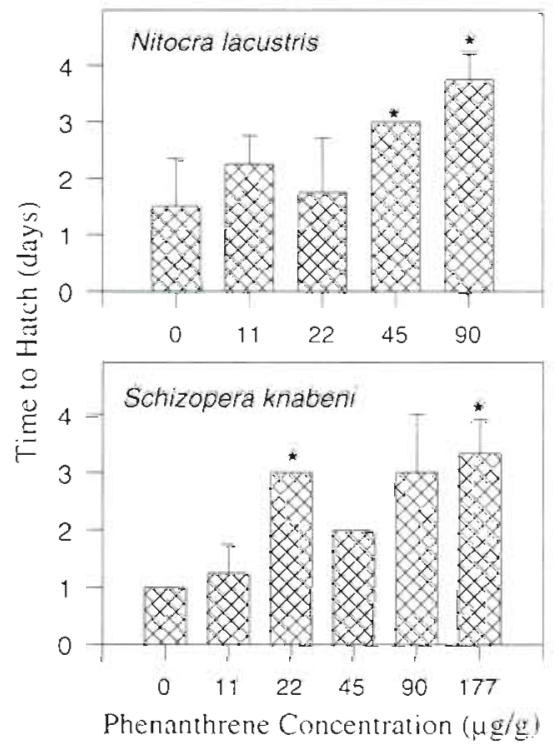

Fig. 5. Nitocra lacustris and Schizopera knabeni. Time to hatching for eggs carried by ovigerous temales obtained in the $10 \mathrm{~d}$ copepodite bioassay. Time is expressed in days from the beginning of the observation period. Error bars show +1 $\mathrm{SD}$ of the mean $(\mathrm{n}=4)_{i}$ * significant difference $(\alpha=0.05)$ from control mean

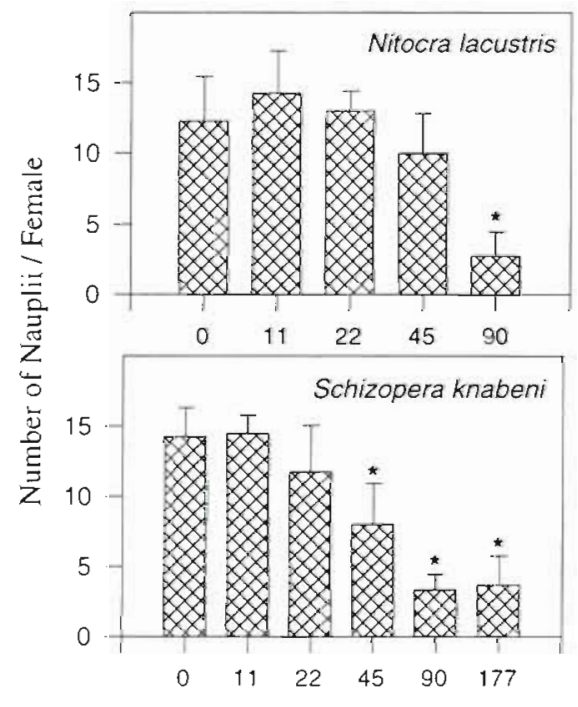

Phenanthrene Concentration $(\mu \mathrm{g} / \mathrm{g})$

Fig. 6. Nitocra lacustris and Schizopera knabeni. Hatching success of ovigerous females obtained in the $1.0 \mathrm{~d}$ copepodite bioassay. Hatching success is expressed as the number of nauplit hatching per female. Error bars show $+1 S D$ of the mean $(n=4)$; significant difference $(\alpha=0.05)$ from control mean

at 45 and $90 \mu \mathrm{g} \mathrm{g}^{-1}$ dry wt (Fig. 5). Schizopera knabeni carrying their first brood of eggs were observed. Hatching occurred after an average period of $1 \mathrm{~d}$ in the con- trol and at significantly longer periods (up to $3.3 \mathrm{~d}$ ) at 22 and $177 \mathrm{\mu g} \mathrm{g}^{-1}$ (Iry wt (Fig. 5). Delayed egg hatching represented an increase in the mean age at first reproduction from 19 days in the control to $21.3 \mathrm{~d}$ at $177 \mathrm{\mu g}$ $\mathrm{g}^{-1}$ dry wt. Partial life-cycle observations indicated that eggs hatch after an average of 1 to $2 \mathrm{~d}$ from the time they are extruded, suggesting that the late hatching observed with phenanthrene-exposed females is most likely due to slower embryonic development rather than to delay in when eggs were extruded.

\section{Sublethal toxicity: hatching success}

For Nitocra lacustris, the mean number of nauplii hatching from individual ovigerous females obtained from the copepodite bioassay ranged from 10 to 14.25 in the control and 11,22 and $45 \mu \mathrm{g} \mathrm{g}^{-1}$ dry wt phenanthrene treatments (Fig. 6). A significantly lower mean (2.75 eggs) hatched from females exposed to $90 \mu \mathrm{g} \mathrm{g}^{-1}$ dry wt. For Schizopera knabeni, the mean number of nauplii hatching from exposed females was highest in the control (14.5) and significantly lower than the control (as low as 3.7) at 45,90 and $177 \mu \mathrm{g} \mathrm{g}^{-1}$ dry wt. Clutch size, not directly measured because of the experimental design, appeared to be similar among all $N$. lacustris and $S$. knabeni ovigerous females used in these observations.

\section{DISCUSSION}

\section{Effects on survival}

Ten day $\mathrm{LC}_{50}$ values were obtained from tests starting with different life stages of Schizopera knabeni and Nitocra lacustris and indicated markedly different patterns of life-stage-specific sensitivity for the 2 species (Table 1). For $S$ knabeni, the lowest $10 \mathrm{~d}$ $\mathrm{LC}_{50}$ value was obtained when exposure was initiated with early naupliar stages, followed by early copepodite stages, and adult males and pre-adult females. This apparent gradual decrease in sensitivity to phenanthrene as larval development progresses is supported by statistical analysis. No sex-specific differences in sensitivity were apparent, as indicated by very similar $10 \mathrm{~d} \mathrm{LC}_{50}$ values for males and females. The $10 \mathrm{~d}^{2} \mathrm{LC}_{50}$ value for adult copepods was approximately 4 times higher than that for nauplii and 2 times higher than that for copepodites. For N. lacustris, the lowest $10 \mathrm{~d} \mathrm{LC}_{50}$ value was for copepodites and was increasingly higher for nauplii, adult male, and adult females. Statistical analysis indicated a higher tolerance of adult females but a lack of differences among all other life stages. Sex-specific differ- 
ences were observed, with females significantly more tolerant than males.

Early larval stages of numerous species of crustaceans are more sensitive than adults to crude oil (Katz 1973, Karinen \& Rice 1974, Mecklenburg et al. 1977, Cucci \& Epifanio 1979, Capuzzo et al. 1984) and phenanthrene (Laughlin \& Neff 1979). The molting process may be involved; higher PAH tissue burden was found in newly molted compared to intermolt crabs perhaps as a consequence of increased water uptake and integument permeability at ecdysis or decreased PAH biotransformation rate during the molt process (Mothershead \& Hale 1992). Naupliar stages of meiobenthic copepods were consistently the most sensitive in aqueous exposures to heavy metals (Verriopoulus \& Moraitou-Apostolopoulou 1982, O'Brien et al. 1988, Hutchingson et al. 1994) and chlorpyrifos (Green et al. 1996). Higher tolerance of female copepods, as observed with $N$. lacustris, has been reported for other species of copepods in aqueous and sediment exposures to PCBs (polychlorinated biphenyls) and petroleum hydrocarbons (Dalla Venezia et al. 1981, DiPinto et al. 1993, Carman \& Todaro 1996) and has been speculated to be related to the elimination of hydrophobic contaminants via egg production (DiPinto et al. 1993).

Overall, Nitocra lacustris was more sensitive to phenanthrene lethal toxicity than was Schizopera knabeni. The $10 \mathrm{~d} \mathrm{LC}_{50}$ values for $S$ knabeni ranged from 84 to $349 \mu \mathrm{g} \mathrm{g} \mathrm{g}^{-1}$ dry wt $\left(5600\right.$ to $26800 \mu \mathrm{g} \mathrm{goc}{ }^{-1}$ dry wt; where goc is $g$ organic carbon), whereas with $N$. lacustris values ranged from 43 to $105 \mu^{-1}$ g dry wt $\left(2867\right.$ to $7000 \mu \mathrm{g} \mathrm{g}_{o c}{ }^{-1}$ dry wt). Phenanthrene lethal toxicity in sediment exposures is only known for a limited number of species. Comparison of $10 \mathrm{~d} \mathrm{LC} 50$ values (on an organic carbon basis) suggests that all stages of $N$. lacustris and the larval stages of $S$. knabeni are equally or more sensitive than mature or sub-adult individuals of the marine amphipods Eohastorious estuarinus (3820 to $4050 \mu \mathrm{g} g_{o c}{ }^{-1}$ dry wt; U.S. EPA 1993) and Leptocheirus plumosus (6490 to 8200 $\mu \mathrm{g} \mathrm{g}_{o c}{ }^{-1}$ dry wt; U.S. EPA 1993), whereas adult $S$. knabeni are significantly more tolerant. Both $S$. knabeni and $N$. lacustris were more sensitive to phenanthrene than the oligochaete Limnodrilus hoffmeisteri $\left(10 \mathrm{~d} \mathrm{LC}_{50}=42500 \mu \mathrm{g} \mathrm{goc}{ }^{-1}\right.$ dry wt; Lotufo \& Fleeger 1996)

Ultraviolet radiation in sunlight dramatically increases the lethal toxicity of PAHs to infaunal organisms due to the formation of excited states of the parent molecule, even in the presence of sediment (Ankley et al. 1994). In order to prevent the confounding effect of this phenomenon, all experiments in this study were conducted in the dark. It has been demonstrated, however, that several PAH congeners, among them phenanthrene, are not phototoxic (Newsted \& Giesy 1987). Mechanistic explanations for the prediction of photo-induced toxicity to specific congeners are provided by Mekenyan et al. (1994).

\section{Effects on reproduction and development}

Phenanthrene delayed embryonic and larval development in Nitocra lacustris and Schizopera knabeni (Figs. 3, 4 \& 5). Decreases in developmental and growth rates have been reported for other crustaceans in aqueous exposures to phenanthrene (Laughlin \& Neff 1979, Geiger \& Buikema 1982) and crude or fuel oils (Capuzzo et al. 1984 and references therein). Reduced feeding and decreased scope for growth have been demonstrated in crustaceans exposed to petroleum hydrocarbons (Wang \& Stickle 1987, Lotufo 1997) and are likely related to delayed development and low growth rate. In addition, Capuzzo et al. (1984) showed that delayed development and lower growth rate in larval lobster exposed to petroleum hydrocarbons was related to alterations in normal patterns of lipid storage, utilization and synthesis. Copepod developmental rate and onset of reproduction were also delayed under aqueous exposure to 2,4-dichlorophenol and 4-chlorophenol (Kuiper \& Hanstveit 1984) and insecticides (Allan \& Daniels 1982, Savitz et al. 1994, Wright et al. 1996).

The sex ratio of adult copepods on Day 10 in the phenanthrene treatments of the Nitocra lacustris nauplius and the Schizopera knabeni copepodite bioassays was skewed, although not significantly, towards males (Figs. 3 \& 4). There are several possible ways that PAHs might have influenced sex ratio in these $10 \mathrm{~d}$ experiments. Environmental sex determination has been suggested for copepods (Fleeger \& Shirley 1990), and may be influenced by PAHs, but a more likely explanation involves the effect of PAHs on developmental rate. Male copepodites attain the adult stage earlier than females (Bergmans 1981). Because development was faster in controls, copepodites of both sexes attained adult stage during the short duration of the experiment. If the exposure period were longer, female copepodites in phenanthrene treatments would probably have developed to adults as well. No previous studies have reported PAH effects on sex ratio in crustaceans.

Nitocra lacustris and Schizopera knabeni early-stage copepodites exposed to sediment-associated phenanthrene for $10 \mathrm{~d}$ that developed into ovigerous females were isolated and observed in clean $25 \%$ ASW for egg hatching. Although there was no apparent difference in clutch size, broods from phenanthrene-exposed females produced significantly fewer nauplii as com- 
pared to broods from control females (Fig. 6). Hatching success was significantly reduced by approximately $75 \%$ in relation to the control at $90 \mu^{-1} \mathrm{~g} \mathrm{~g}^{-1}$ dry wt for both $N$. lacustris and $S$. knabeni. Nauplius survival at $90 \mu \mathrm{g} \mathrm{g}^{-1}$ dry wt was reduced by only approximately $40 \%$ in both species, suggesting that the egg stage is more sensitive than larval stages to phenanthrene toxicity. Low egg-hatching success has been observed for ovigerous females of a planktonic copepod (Cowles \& Remillard 1983) and grass shrimp (Tatem 1977, Fisher \& Foss 1993) following exposure to petroleum hydrocarbons.

Phenanthrene did not have a negative impact on Schizopera knabeni clutch size number of eggs per brood), except at $492 \mu \mathrm{g} \mathrm{g}^{-1}$ dry wt. The number of nauplii and copepodites produced per surviving female of $S$. knabeni, however, decreased in a concentration-dependent fashion (Fig. 2). Offspring production was significantly reduced by $24 \%$ of control levels at $22 \mu \mathrm{g} \mathrm{g}^{-1}$ dry wt. Because neither clutch size, hatching success, nor naupliar survival were adversely affected at $22 \mu \mathrm{g}$

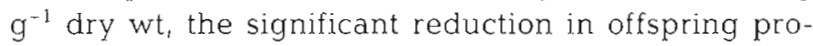
duction was probably a consequence of decreased brood production rate. However, decreased hatching success and larval survivorship must have also contributed to reduce the final number of nauplii and copepodites at higher concentrations. The fraction of the realized offspring comprised of copepodites tended to decrease with increasing phenanthrene concentrations (Fig. 2), likely due to delayed formation and hatching of the earliest broods and slow metamorphosis.

Nitocra lacustris offspring production was affected by phenanthrene to a lesser extent than Schizopera knabeni. The reproductive output of surviving females was significantly decreased only at $90 \mu \mathrm{g} \mathrm{g} \mathrm{g}^{-1}$ dry wt (30\% of control level) in $N$. lacustris. The $10 \mathrm{~d}$ copepodite bioassay indicated that copepodite survival at $90 \mu \mathrm{g} \mathrm{g}^{-1}$ dry wt was also decreased to $30 \%$ of control level, suggesting that early-stage mortality significantly contributed to the overall decrease in offspring production over the 10 days. Phenanthrene also likely inhibited hatching, as the fraction of surviving females that were ovigerous at test termination was significantly higher at $90 \mu \mathrm{g} \mathrm{g}^{-1}$ dry wt $(80 \%)$ than in the control $(8 \%$; data not shown). The fraction of offspring attaining copepodite stages was significantly lower in phenanthrene treatments than in the control, probably because of reduced juvenile survival and developmental rate.

\section{Ecological significance}

Survival and offspring production were not monitored for the entire life cycle of female copepods, pre- venting the construction of a full life table. Results from this study nevertheless reveal that phenanthrene concentrations much lower than the adult $10 \mathrm{~d} \mathrm{LC}_{50}$ value will reduce hatching success, early-stage survivorship, rate of development, sexual maturation and fecundity of some benthic harpacticoids. Offspring production of Schizopera knabeni, for example, was significantly decreased at concentrations as low as $22 \mu \mathrm{g} \mathrm{g}^{-1}$ dry wt, whereas adult survival was significantly decreased only at $492 \mathrm{\mu g} \mathrm{g} \mathrm{g}^{-1}$ dry wt. But in Nitocra lacustris, effects on survival and reproduction occurred at similar contaminant levels. This species-specific difference makes it difficult to generalize our results to field settings. Major effects on either mortality or reproduction occurred at concentrations from about 20 to $40 \mu \mathrm{g} \mathrm{g}^{-1}$ dry wt for both species. Total PAH concentration in heavily contaminated estuarine sediments may reach or exceed this level (Kennish 1992), but such contamination occurs in only a relatively small percentage of estuarine sites (Daskalakis \& O'Conner 1995). Long et al. (1995) determined sediment concentrations frequently associated with adverse effects (effects-range median, or ER-M guideline values) for phenanthrene to be in the range of $2.25 \mu \mathrm{g} \mathrm{g}^{-1}$ dry wt at $1.5 \%$ SOC. The U.S. EPA (1993) has proposed a salt-water sediment quality criteria (SQC) for phenanthrene of $3.75 \mu \mathrm{g} \mathrm{g}^{-1}$ dry wt at $1.5 \%$ SOC (SOC of the sediment used in this study) Since no statistically significant effect was detected at the lowest concentration used in our toxicity bioassays ( $11 \mu \mathrm{g} \mathrm{g}^{-1}$ dry $\left.w \mathrm{t}\right)$, the SQC and the ER-M would be protective for both $N$. lacustris and $S$. knabeni. Fleeger \& Chandler (1983) reported that $N$. lacustris was unaffected by crude oil application to salt-marsh sediments in the only known field study involving either species used in our experiments.

The results of this study suggest that, for Schizopera knabeni, offspring production and age at first reproduction are the most sensitive life-cycle variables (significant effect $22 \mathrm{\mu g} \mathrm{g}^{-1} \mathrm{dry}$ wt), followed by egg hatching success (significant effect at $45 \mu \mathrm{g} \mathrm{g}^{-1}$ dry wt). For Nitocra lacustris, results suggest that early-stage survival is the most sensitive variable (significant effect at $22 \mu g g^{-1}$ dry wt), followed by egg hatching and offspring production (significant effect at $90 \mathrm{\mu g} \mathrm{g}^{-1}$ dry wt). A prediction of which life-history-related endpoin.t is the most relevant from an ecotoxicological perspective cannot be attempted with the available data from this study. Based on complete life-cycle experiments with soil nematodes, Kammenga et al. (1996) showed that although a reduction in the duration of the reproductive period (period of entire life-cycle during which viable offspring was produced) by cadmium was the most pronounced $(45 \%)$ among several life-cycle variables, it did not have an effect on fitness (defined as $r_{\mathrm{m}}$ ). Prolongation of the juvenile period by $7.5 \%$ or a 
reduction in offspring production by $22 \%$, however, had the greatest impact, decreasing fitness by $5 \%$. Only a full life-table study accompanied by a deterministic model designed to relate changes in individual variables to fitness would indicate the ecological significance of each variable individually (Kammenga et al. 1996). Life-table experiments exposing copepods to individual contaminants have been successful (Daniels \& Allan 1981, Allan \& Daniels 1982, Bechmann 1994, Green \& Chandler 1996). Full life-cycle sediment exposures of benthic copepods to PAHs and other contaminants accompanied by a deterministic model analysis as in Kammenga et al. (1996) is encouraged for a better understanding of the ecological implication of sublethal contaminant impact on life-history parameters.

Acknowledgements. We are grateful to Drs K. Carman, K. Brown and $W$. Stickle for critical comments on the manuscript. We also thank Lory Moranto and Tom Luong for helping with chemical analysis. This research was funded by LSU's Coastal Marine Institute and the Minerals Management Service (U.S. Department of Interior). G.R.L. was financially supported by CNPq. Brazlian Federal Government.

\section{LITERATURE CITED}

Allan JD, Daniels RE (1982) Life table evaluation of chronic exposure of Eurytemora affinis (Copepoda) to Kepone. Mar Biol 66:179-184

Ankley GT, Collyard SA, Monson PD, Kosian PA (1994) Influence of ultraviolet light on the toxicity of sediments contaminated with polycyclic aromatic hydrocarbons. Environ Toxicol Chem 13:1791-1796

Bechmann RK (1994) Use of life tables and LC 5 tests to evaluate chronic and acute toxicity effects of copper on the marine copepod Tisbe furcata (Baird). Environ Toxicol Chem 13(9): 1509-1518

Bengtsson BE, Tarkpea M (1995) A 96-h acute toxicity test with the brackish water crustacean Nitocra spinipes Boeck: assessment of chemicals, products, and effluents. Environ Toxicol Water Qual 10:147-150

Bergmans M (1981) A demographic study of the life cycle of Tisbe furcata (Baird, 1837) (Copepoda: Harpacticoida). J Mar Biol Assoc UK 61:691-705

Capuzzo JM, Lancaster BA, Sasaki GC (1984) The effects of petroleum hydrocarbons on lipid metabolism and energetics of larval development and metamorphosis in the American lobster (Homarus americanus Milne Edwards). Mar Environ Res 14:201-228

Carman KR, Fleeger JW, Means JC, Pomarico S, McMillin DJ (1995) Experimental investigation of the effects of polynuclear aromatic hydrocarbons on an estuarine sediment food web. Mar Environ Res 40:289-318

Carman KR, Todaro MA (1996) Influence of polycyclic aromatic hydrocarbons on the meiobenthic-copepod community of a Loulsiana salt marsh. J Exp Mar Biol Ecol 198: $37-54$

Chandler GI (1990) Effects of sediment-bound residues of the pyrethroid insecticide fenvalerate on survival and reproduction of meiobenthic copepods. Mar Environ Res 29: $65-76$
Chandler GT, Green AS (1996) A 14 -d harpactıcoid copepod reproduction bioassay for laboratory and field contaminated muddy sediments. In: Ostrander GK (ed) Techniques in aquatic toxicology. CRC Press, Boca Raton, p 23-39

Cowles TJ, Remillard JF (1983) Effects of exposure to sublethal concentrations of crude oil on the copepod Centropages hamatus. I. Feeding and egg production. Mar Biol 78:45-51

Cucci TL, Epifanio CE (1979) Long term effects of water soluble fractions of Kuwait crude oil on the larval and juvenule development of the mud crab Eurypanopeus depressus. Mar Biol 55:215-220

Dalla Venezia L, Fossato VU, Scarfı S (1981) Characteristics of suspensions of PCB Aroclor 1254 and Corexit 7664 and their short- and long-term effects on Tisbe bulbisetosa. Comm Int L'explor Mer Med V's J Etud Pollut Cagliari 32 : $613-620$

Damels RE, Allan JD (1981) Life table evaluation of chronic exposure to a pesticide. Can J Fish Aquat Sci 38:485-494

Daskalakis KD, O'Connor TP (1995) Distribution of chemical concentrations in US coastal and estuarine sediment. Mar Environ Res 40:381-398

DiPinto LM, Coull BC. Chandler GT (1993) Lethal and sublethal effects of the sediment-associated PCB Aroclor 1254 on a meiobenthic copepod. Environ Toxicol Chem 12: $1909-1918$

Donkin P, Widdows J, Evans SV, Worrall CM, Carr M (1989) Quantitative structure-activity relationships for the effect of hydrophobic organic chemicals on rate of feeding by mussels (Mytilus edulis). Aquat Toxicol 14:277-294

Emery VL, Dillon TM (1996) Chronic toxicity of phenanthrene to the marine polychaete worm, Nereis (Neanthes) arenaceodentata. Bull Environ Contam Toxicol 56:265-270

Fisher WS, Foss SS (1993) A simple test for toxicity of number 2 fuel oil and oil dispersants to embryos of grass shrimp. Palaemonetes pugio. Mar Pollut Bull 26:385-391

Fleeger JW, Chandler GT (1983) Meiofaunal responses to an experimental oil spill in a Louisiana salt marsh. Mar Ecol Prog Ser 11:257-264

Fleeger JW, Shirley TC (1990) Meiofaunal responses to sedimentation from an Alaskan spring bloom. Il. Harpacticold population dynamics. Mar Ecol Prog Ser 59:239-247

Geiger JG, Buikema AL Jr (1981) Oxygen consumption and filtering rate of Daphnia pulex after exposure to water-soluble fractions of naphthalene, phenanthrene, No. 2 fuel oil and coal-tar creosote. Bull Environ Contam Toxicol 27 : $783-787$

Geiger JG, Buikema AL Jr (1982) Hydrocarbons depress growth and reproduction of Daphnia pulex (Cladocera). Can J Fish Aquat Sc 39:830-836

Green AS, Chandler GT (1996) Life-table evaluation of sediment-associated chlorpyrifos chronic toxicity to the benthic copepod, Amphiascus tenuiremis. Arch Environ Contam Toxicol 31:77-83

Green AS, Chandler GT. Piegorsch WW (1996) Life stage specifuc toxicity of sediment-associated chlorpyrifos to a marne, infaunal copepod. Environ Toxicol Chem 15: $1182-1188$

Hamilton MA، Russo RC, Thurston RV (1977) Trummed Spearman-Karber method for estimating median lethal concentrations in toxicity bioassays. Environ Sci Technol 11 $714-719$

Hutchınson TH. Willıams TD, Eales GJ (1994) Toxicity of cadmium, hexavalent chromium and copper to marine fish larvae (Cyprinodon variegatus) and copepods (Tisbe battagliai). Mar Environ Res 38:275-290 
Kammenga JE, Busschers M, Van Straalen NM, Jepson PC, Bakker J (1996) Stress induced fitness reduction is not determined by the most sensitive life-cycle trait. Funct Ecol 10:106-111

Karinen JF, Rice SD (1974) Effects of Prudhoe Bay oil on molting tanner crabs, Chionocetes bairdi. Mar Fish Rev 36: $31-37$

Katz LM (1973) The effects of water soluble fraction of crude oil on larvae of the decapod crustacean Neopanope texana (Sayi). Environ Pollut 5:199-204

Kennish MJ (1992) Ecology of estuaries: anthropogenic effects. CRC Press, Boca Raton, FL

Kuiper J, Hanstvelt AO (1984) Fate and effects of 4-chlororophenol and 2,4-dichlorophenol in marine plankton communities in experimental enclosure. Ecotoxicol Environ Safety $8: 15-33$

Landrum PF, Dupuis WS, Kukkonen J (1994) Toxicokinetics and toxicity of sediment-associated pyrene and phenanthrene in Diporeia spp.: examination of equilibrium-partitioning theory and residue-based effects for assessing hazard. Environ Toxicol Chem 13:1769-1780

Laughlin RB Jr, Neff JM (1979) Interactive effects of salinity, temperature and polycyclic aromatic hydrocarbons on the survival and development rate of larvae of the mud crab Rhithropanopeus harrisii. Mar Biol 53:281-291

Laughlin RB Jr, Neff JM (1980) Influence of temperature, salinity, and phenanthrene (a petroleum derived polycyclic aromatic hydrocarbon) on the respiration of larval mud crabs, Rhithropanopeus harrisii. Estuar Coast Mar Sci 10:655-669

Long ER, MacDonald DD, Smith SL, Calder FD (1995) Incidence of adverse biological effects within ranges of chemical concentrations in marine and estuarine sediments. Environ Manag 19:81-97

Lotufo GR (1997) Toxicity of sediment associated PAHs to an estuarine copepod: effects on survival, reproduction and behavior. Mar Environ Res (in press)

Lotufo GR, Fleeger JW (1996) Toxicity of sediment-associaled pyrene and phenanthrene to Limnodrilus hoffmeisteri (Olıgochaeta: Tubificidae). Environ Toxicol Chem 15: $1508-1516$

Mecklenburg TA, Rice SD, Karinen JF (1977) Molting and survival of king crab (Paralithodes camtschatica) and coonstripe shrimp (Pandalus hypsinotus) larvae exposed to Cook Inlet crude oil water-soluble fraction. In: Wolfe DA (ed) Fate and effects of petroleum hydrocarbons in marine organisms and ecosystems. Pergamon. Press, New York, p 221-228

This article was presented by S. P. Meyers (Senior Editorial Advisor), Baton Rouge, Louisiana, USA
Mekenyan OG, Ankley GT, Veith GD, Call DJ (1994) QSARs for photoinduced toxicity: I. Acute lethality of polycyclic aromatic hydrocarbons to Daphnia magna. Chemosphere 28:567-582

Mothershead TRI, Hale RC (1992) Influence of ecdysis on the accumulation of polycyclic aromatic hydrocarbons in field exposed blue crabs Callinectes sapidus. Mar Environ Res 33:145-156

Newsted JL. Giesy JP (1987) Predictive? models for photoinduced acute toxicity of polycyclic aromatic hydrocarbons to Daphnia magna, Strauss (Cladocera, Crustacea). Env1ron Toxicol Chem 6:445-461

O'Brien P, Feldman H, Grill EV, Lewis AG (1988) Copper tolerance of the life history stages of the splashpool copepod Tigriopus callfornicus (Copepoda, Harpacticoida). Mar Ecol Prog Ser 44:59-64

Savitz JD, Wright DA, Smucker RA (1994) Toxic effects of the insecticide diflubenzuron (Dimilin ${ }^{2}$ ) on survival and development of nauplii of the estuarine copepod, Eurytemora affinis. Mar Environ Res 37:297-312

Steel RG, Torrie JW (1960) Principles and procedures of statistics, with special reference to the biological sciences. McGraw-Hill, New York

Strawbridge S, Coull BC. Chandler GT (1992) Reproductive output of a meiobenthic copepod exposed to sediment-associated fenvalerate. Arch Environ Contam Toxicol 23:295-300

Tatem HE (1977) Accumulation of naphthalenes by grass shrimp: effects on respiration, hatching and larval growth. In: Wolfe DA (ed) Fate and effects of petroleum hydrocarbons in marine ecosystems and organisms. Pergamon, New York, p 201-209

U.S. EPA (1993) Sediment quality criteria for the protection of benthıc organisms: phenanthrene. EPA 882-R-93-012. Office of Water and Office of Research Development, Washington, DC

Verriopoulos G, Moraitou-Apostolopoulou M (1992) Differentiation of the sensitivity to copper and cadmium in different life stages of a copepod. Mar Pollut Bull 13:123-125

Wang SY, Stickle WB (1987) Bioenergetics, growth and molting of the blue crab, Callinectes sapidus, exposed to the water-soluble fraction of South Louisiana crude oil. In: Vernberg WB, Calabrese A, Thurberg FP, Vernberg FJ (eds) Pollution and physiology of estuarine organisms. University of South Carolina Press, Columbia, p 107-126

Wright DA, Savitz JD, Dawson R, Magee J, Smucker RA (1996) Effect of diflubenzuron on the maturation and reproductive success of the copepod Eurytemora affinis. Ecotoxicology 5:47-58

Manuscript first received: November 6, 1996 Revised version accepted: March 18, 1997 